\title{
EVALUATING THE ACCUMULATION TREND OF L-DOPA IN DARK-GERMINATED SEEDS AND SUSPENSION CULTURES OF Phaseolus vulgaris L. BY AN EFFICIENT UV-SPECTROPHOTOMETRIC METHOD
}

\author{
Samira Rahmani-Nezhad ${ }^{a}$, Shima Dianat ${ }^{\mathrm{a}}$, Mina Saeedi ${ }^{\mathrm{a}, \mathrm{b}}$, Maliheh Barazandeh Tehranic ${ }^{\mathrm{c}}$, Adel Ghadiri ${ }^{\mathrm{d}}$ and Abbas \\ Hadjiakhoondi ${ }^{\mathrm{a}, \mathrm{e}, *}$ \\ aMedicinal Plants Research Center, Faculty of Pharmacy, Tehran University of Medical Sciences, Tehran, Iran \\ bPersian Medicine and Pharmacy Research Center, Tehran University of Medical Sciences, Tehran, Iran \\ 'Department of Medicinal Chemistry, Faculty of Pharmacy, Tehran University of Medical Sciences, Tehran, Iran \\ ${ }^{\mathrm{d}}$ Khomein National Bean Research Station, Arak, Iran \\ eDepartment of Pharmacognosy, Faculty of Pharmacy, Tehran University of Medical Sciences, Tehran, Iran
}

Recebido em 30/08/2017; aceito em 12/12/2017; publicado na web em 01/02/2018

\begin{abstract}
Seed germination and plant cell cultures provide an alternative mean for producing secondary metabolites. The present study is an attempt to evaluate the effect of seed dark germination and some elicitors and precursors on the production of L-DOPA in Phaseolus vulgaris L. Callus cultured on Murashige and Skoog medium supplemented with various concentrations of different plant growth regulators. L-DOPA produced was quantified by UV-spectrophotometric method. In this study, a user-friendly, quick, and economical UV-spectrophotometric method was described to determine L-DOPA content in extracts from 33 biotypes of Phaseolus vulgaris L. The method is based on the nitrosation of L-DOPA to form a yellow solution and then formation of a red solution by adding base which is measurable at $470 \mathrm{~nm}$. According to our statistical studies, this method showed high efficiency and selectivity for quantitative determination of L-DOPA in herbal extracts from dried plant seeds, dark-germinated seeds and callus cultures. L-DOPA content in dark-germinated seeds and suspension cultures increased significantly to approximately several-fold compared to the control. The implication from this study is that elicitor treatment and precursor feeding of Phaseolus vulgaris L. can significantly improve the parkinson's relevant L-DOPA content.
\end{abstract}

Keywords: callus cultures; dark germination; L-DOPA; spectrophotometric determination; Phaseolus vulgaris L.

\section{INTRODUCTION}

Parkinson's disease is a chronic central nervous system disorder caused by the progressive death of dopamine-producing nerve cells in the basal ganglia of the brain. This leads to an imbalance between dopamine and acetylcholine with probable decrease of dopamine in the brain. ${ }^{1}$ L-DOPA or levodopa (3,4-dihydroxy-L-phenylalanine) is an effective and standard drug therapy for the control of symptoms in patients with Parkinson's disease. It is orally administered amino acid that passes through the blood brain barrier (BBB) easily and converts to dopamine. ${ }^{2}$ L-DOPA, as a secondary metabolite, was first isolated from the fruit of Vicia faba. ${ }^{3}$ Stizolobium deeringianum and Mucuna pruriens have also been reported as natural sources of levodopa, besides broad bean. Mucuna pruriens beans have been used as an efficacious herbal drug for PD treatment in India for many years. ${ }^{4}$ L-DOPA is accumulated in large amounts in some legumes which has led to use various techniques to enhance it; for example seed germination, UV or microwave treatment of dry seeds, solidstate bioconversion system using the food grade fungus Rhizopus oligosporus and plant cell as well as tissue culture. ${ }^{5}$ Each of these conditions can significantly improve the phenolic antioxidant activity and L-DOPA content.

Quantitative determination of L-DOPA in its dosage form has been continuously considered in the literature, since L-DOPA can be oxidized rapidly in the presence of moisture or atmospheric oxygen and reduce its activity. In this regard, various analytical methods such as HPLC technique with diode-array, fluorescence, electrochemical and UV-detection, ${ }^{6-17}{ }^{1} \mathrm{H}-\mathrm{NMR}$ analysis,${ }^{18}$ chemiluminescence, ${ }^{19}$ spectrofluorimetry, ${ }^{20}$ ion-exchange column chromatography, ${ }^{21}$

*e-mail: drabbhadji@gmail.com
HPTLC, ${ }^{22}$ gas chromatography, ${ }^{23}$ radioimmunoassay, ${ }^{24}$ titrimetric,,${ }^{25}$ voltametric determination, ${ }^{26}$ electrochemistry methods, ${ }^{27}$ potentiometry, ${ }^{28}$ LC-MS-MS, ${ }^{29}$ and TLC have been developed. ${ }^{30}$ However, most of these methods are complex and hence lack the simplicity needed for routine applications. They usually need cumbersome, expensive or sophisticated instruments, and precise control through the experimet.

The use of UV-Vis spectrophotometry and colorimetric assay has been highly developed over the last few years especially in the field of pharmaceutical analysis since they provide instantaneous, rapid, available, cost-effective and high precision methods. ${ }^{31}$ Considering the fact that L-DOPA obtained from natural resources specially Mucuna pruriens L. has shown more potency comparing with synthetic product, ${ }^{32}$ development of efficient methods for detection of L-DOPA in herbal extracts is highly in demand. Up to now, several spectroscopic methods using various chromogenic reagents have been provided for detection of L-DOPA or other catecholamines in non herbal sources. They mainly are based on oxidation of hydroxyl groups or interaction of amino acid moeity with the corresponding reagent. ${ }^{33}$ However, there is a few reports on the evaluation of L-DOPA in herbal extracts using chromatophic and spectrofluorimetric procedures. ${ }^{34}$ In this regard, we developed a user-friendly, simple, rapid, and economical UV-spectrophotometric method for the estimation of L-DOPA in a wide range of biotypes of Phaseolus vulgaris L. This method is based on the nitrosation reaction of L-DOPA in precence of sodium nitrate solution in acidic medium which forms an unstable yellow solution, the solution then turns to a stable red one by adding base which is measurable at 470 $\mathrm{nm}$. It is worth noting that, one of the most prominent features of this method is its high selectivity against L-DOPA compared to other phenolic compounds which is characterized by the formation 
of a deep red color in the reaction solution. We have also studied accumulation trend of L-DOPA in seed dark germination and callus culture of Phaseolus vulgaris L. in different conditions to obtain insight into their effects on L-DOPA production. As there are no reports available to date on the enhancement of L-DOPA by elicitors or precursors in the Phaseolus vulgaris L., this study represents the first successful seeds dark germination and cell culture based approach for the production of L-DOPA and determination of it in Phaseolus vulgaris L.

\section{EXPERIMENTAL SECTION}

\section{Chemicals and reagents}

All chemicals and reagents used were of analytical grade and obtained from Merck. All solutions including sodium nitrite (3\%), hydrochloric acid $\left(1 \mathrm{~mol} \mathrm{~L}^{-1}\right)$, and sodium hydroxide $\left(1 \mathrm{~mol} \mathrm{~L}^{-1}\right)$ were freshly prepared. Standard L-DOPA (purity $>99.5 \%$ ) was a gift sample from Ramopharmin Co, Tehran, Iran.

\section{Instrumentation}

Absorption measurements were performed on a double beam UV-Vis spectrophotometer (160A, Shimadzu, Japan) with a fixed $2 \mathrm{~nm}$ bandwidth and $1.0 \mathrm{~cm}$ matching quartz cell was utilized for measuring absorbance. Spectra were recorded over the wavelength range $200-800 \mathrm{~nm}$.

\section{Plant material and preparation of extract}

33 Iranian biotypes of Phaseolus vulgaris L. were obtained from National Research Station of Khomein, Markazi province, Iran; most of the seeds were black. M. pruriens seeds were purchased from Indian market. It was identified at Khomein National Bean Research Station (Figure 1). To prepare the extract, at first, one gram of each plant sample (dried seed, seeding and callus) was grounded to powder and soaked in solution $(10 \mathrm{~mL})$ containing $0.1 \mathrm{~N} \mathrm{HCl}-$ Ethanol (1:1) in darkness. After five days, each solution was filtered using whatman filter paper (No. 1) and centrifuged at $3500 \mathrm{rpm}$ for $10 \mathrm{~min}$. The resulting solution was concentrated under vacuum and freeze-dried. L-DOPA content was estimated in each sample using spectrophotometric method.

\section{Calibration curve of standard L-DOPA}

A stock solution of L-DOPA was prepared by dissolving $10 \mathrm{mg}$ of L-DOPA in a $100 \mathrm{~mL}$ volumetric flask. A series of nine $25-\mathrm{mL}$ volumetric flasks respectively containing $1,2,3,4,5,6,7,8$, and $9 \mathrm{~mL}$ of stock solution were prepared. Then, sodium nitrite $(3 \%, 2 \mathrm{~mL})$ and hydrochloric acid $\left(1 \mathrm{~mol} \mathrm{~L}^{-1}, 1 \mathrm{~mL}\right)$ were added to those volumetric flasks, left to stand 5 min (turned yellow), rendered alkaline with sodium hydroxide ( $1 \mathrm{~mol} \mathrm{~L}^{-1}, 3 \mathrm{~mL}$ ), left to stand $5 \mathrm{~min}$ (turned red), and finally was diluted to the corresponding volume with distilled water. Next, $\lambda_{\max }$ was determined by scanning one of the solutions in the range of 400-800 $\mathrm{nm}$ using a blank (containing the same components without analyte) and $\lambda_{\max }=470 \mathrm{~nm}$ was obtained. Finally, the absorbance of all the solutions was measured at $470 \mathrm{~nm}$ and the related calibration curve was plotted to determine the linearity in the concentration range of $4-36 \mu \mathrm{g} / \mathrm{mL}$ and regression value of 0.9978 .

\section{Estimation of L-DOPA in the herbal extract}

To determine the L-DOPA content of herbs, at least 400 mg of freeze-dried powders made from extracts of dried seeds, dried germinated seeds and dried calluses were transferred to $25-\mathrm{mL}$ volumetric flask separately and distilled water $(5 \mathrm{~mL})$ was added to the flask. It was sonicated for $5 \mathrm{~min}$ and the mixture was filtered using whatman filter paper (No. 1). L-DOPA content of each concentrate was estimated using the above validated spectrophotometric method.

\section{Seed dark germination}

Seeds (Ks10001, Ks10008, Ks10017, Ks10023, Ks10025, Ks10032, and Ks 51273) were soaked individually in distilled water for $24 \mathrm{~h}$ with slow shaking on an orbital shaker and then they were germinated in flats which were lined with moist paper towels. The flats were covered with aluminum foil and the seeds were germinated in the dark. The germinating seeds were kept moist with distilled water and the assays were performed daily for the next 12 days. After 12 days of germination, signs of growth were appeared and the first pair of leaves emerged. The L-DOPA content of the dark germinating sprouts was determined in the $3^{\text {th }}, 6^{\text {th }}, 9^{\text {th }}$, and $12^{\text {th }}$ days.

\section{Culture medium and conditions}

MS basal medium supplemented with 3\% (w/v) sucrose was used for all in vitro culture studies. The $\mathrm{pH}$ of the medium was adjusted to 5.8 prior to adding $0.8 \%(\mathrm{w} / \mathrm{v})$ agar and autoclaved at $121^{\circ} \mathrm{C}$ for 20 min. Cultures were incubated with a $16 \mathrm{~h}$ photoperiod by cool white fluorescent lamps $\left(25 \mu \mathrm{mol} \mathrm{m} \mathrm{m}^{-2}\right)$ at $25^{\circ} \mathrm{C}$.

\section{Callus induction and suspension cell cultures}

The seeds of Phaseolus vulgaris L. with Ks51102 sample's code were chosen randomly and sterilized with water for $20 \mathrm{~min}, 70 \%$ ethanol for $1 \mathrm{~min}$ and $0.1 \%$ mercuric chloride $\left(\mathrm{HgCl}_{2}\right)$ for $5 \mathrm{~min}$, followed by washing with sterile distilled water 5-6 times to remove traces of $\mathrm{HgCl}_{2}$. They were germinated on basal Murashige and Skoog (MS) medium. ${ }^{35}$ Callus was induced from in vitro leaf tissue explants cultured on MS medium supplemented with various concentrations of 2,4-dichlorophenoxyacetic acid (2,4-D) $(0.50,1.50,2.00,4.50$, $11.00,22.50$ and $45.00 \mu \mathrm{mol} \mathrm{L}-1)$; indole acetic acid (IAA) $(0.50,1.50$, $3.00,5.50,14.00,28.00$, and $\left.57.50 \mu \mathrm{mol} \mathrm{L}^{-1}\right), 6$-benzylaminopurine BA $\left(0.40,1.50,2.00,4.50,11.00,22.50\right.$, and $\left.44.00 \mu \mathrm{mol} \mathrm{L}^{-1}\right)$, and 2-isopentenyl adenine (2-iP) $(0.60,1.50,3.00,4.50,12.00,24.50$, and $50.00 \mu \mathrm{mol} \mathrm{L}^{-1}$ ).

\section{Callus growth}

The growth of the callus and its biomass was measured in fresh (FW g L ${ }^{-1}$ ) and dry weight (DW g L ${ }^{-1}$ ) by standard method. ${ }^{36} \mathrm{FW}$ of callus was measured after removing the excess moisture and agar adhering to the callus surface using blotting paper. DW of callus was determined by drying the callus in hot air oven at $60{ }^{\circ} \mathrm{C}$ for $24 \mathrm{~h}$ and was expressed in $\mathrm{g} \mathrm{L}^{-1} \mathrm{DW}$ culture.

\section{Preparation and application of elicitors and precursors to cell cultures}

Methyl jasmonate (MJ) (50, 100, 150, 200 and $\left.250 \mu \mathrm{mol} \mathrm{L}^{-1}\right)$ was dissolved in sterile distilled water, and L-tyrosine (50, 100, 150, 200 and $250 \mathrm{mmol} \mathrm{L}^{-1}$ ) was prepared by dissolving initially with 1 or 2 drops of $\mathrm{NaOH}(1 \mathrm{~N})$ then diluted with sterile double distilled water to get the final concentrations, $\mathrm{pH}$ was adjusted to 5.8. 

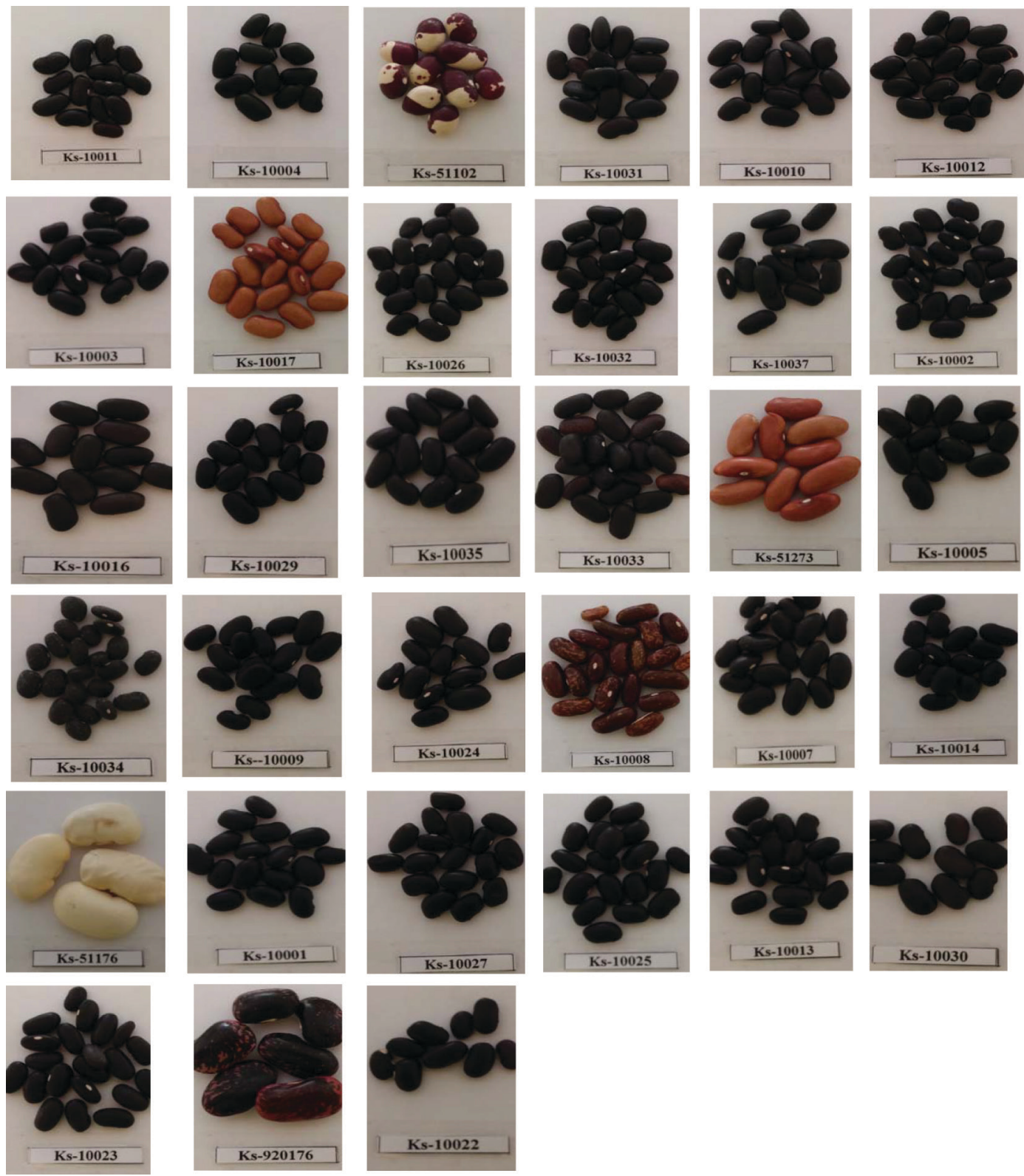

Figure 1. 33 Biotypes of Phaseolus vulgaris L.

\section{RESULTS AND DISCUSSION}

\section{Preliminary studies by thin layer chromatography}

The presence of L-DOPA in the test samples was confirmed by comparing the TLC pattern of testing seeds and the standard L-DOPA using optimized solvent system; butanol: acetic acid: water (4:1:1). After elution with appropriate solvent, the TLC plate was air dried for $10 \mathrm{~min}$, sprayed with a $0.1 \%$ solution of ninhydrin in methanol, and dried at $105{ }^{\circ} \mathrm{C}$ for $5 \mathrm{~min}$. The $\mathrm{Rf}$ values and brownish-pink spots revealed similar profiles (Figure 2).

\section{Selected spectrophotometric method}

Although various spectrophotometric methods have been developed for the detection of L-DOPA, they suffer from different disadvantages such as using expensive reagents, non-aqueous media (leading to precipitation), multi-steps and time consuming procedures, need to heat, instability of the colored species and

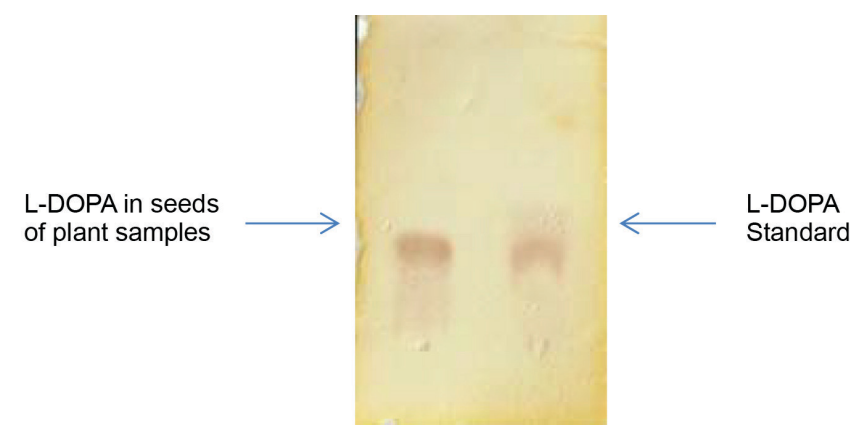

Figure 2. TLC analysis of standard L-DOPA and L-DOPA in seeds of plant samples

poor detection limit. Herein, looking for an efficiennt and practical L-DOPA detection particularly in herbal extracts, we have developed a spectrophotometric method based on the nitrosation of L-DOPA profiting from availability, safety, low cost materials and deep color changes with no precipitated product through the experiment. This 
<smiles>[R]CC(N)C(=O)O</smiles>

Scheme 1. Nitrosation reaction of L-DOPA and Formation of Compounds I and II

method consists of two short steps. In the first step, nitrosation reaction of L-DOPA occurs in the presence of sodium nitrite and $\mathrm{HCl}$ which leads to the formation of unstable yellow color (compound I). In the next step, by adding $\mathrm{NaOH}$ solution, a stable red (compound II), measurable at 470 , is created (Scheme 1, compounds I, II). Stability of compound II is probably due to the contribution of an extra pair of unshared electrons in the interaction with the aromatic nucleus.

The most significant result for this method is the formation of a deep reddish color after adding sodium hydroxide solution, which only has a maximum absorption for the catechol at $470 \mathrm{~nm}$. Absorption curve of nitroso derivative of catechol in alkaline medium is shown in Figure 3.

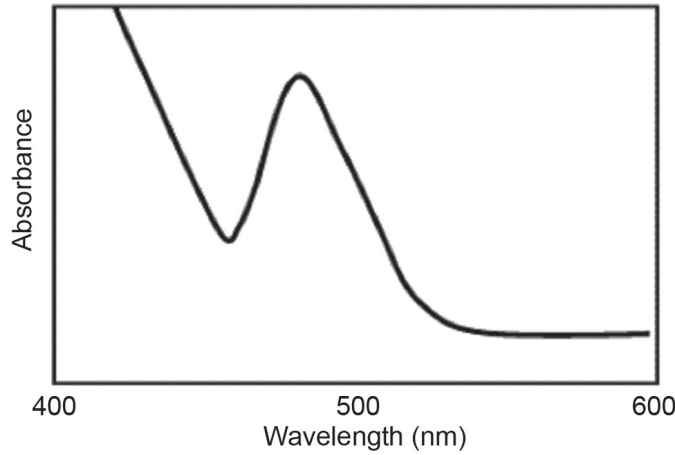

Figure 3. Absorption curve of nitroso derivative of levodopa in alkaline medium

Another important point is the selectivity of this method for the detection of L-DOPA comparing with phenolic compounds such as resorcinol, pyrogallol, phenol, and tyrosine. As can be seen in
Figure 4, formation of deep red solution by L-DOPA makes the method rapid, easy, efficient and selective which can be easily developed for the detection of various catecholic compounds as tested by our group.

\section{Method validation (linearity, detection and quantification limits)}

The spectrophotometric method was validated by evaluating linearity, precision, accuracy, limit of detection (LOD), limit of quantitation (LOQ), and sensitivity of parameters such as molar absorptivity. The linear relationship between absorbance and concentration was indicated by graph obtained using nine standard solutions containing 4, 8, 12, 16, 20, 24, 28, 32, and $36 \mu \mathrm{g} \mathrm{mL} \mathrm{m}^{-1}$ of L-DOPA. Calibration curve and correlation coefficient were obtained by fitting a proper equation using a conventional linear least-squares treatment. It was found that linearity was obeyed in the concentration range of 4-36 $\mu \mathrm{g} \mathrm{mL}^{-1}$ with an excellent coefficient of determination 0.9978. The absorbance values for this concentration range were adjusted by the regression equation line: $\mathrm{A}=0.036 \mathrm{c}+0.0067$ $(\mathrm{A}=\mathrm{mc}+\mathrm{b})$, where $\mathrm{c}$ is the concentration of L-DOPA $\left(\mu \mathrm{g} \mathrm{mL}^{-1}\right)$. It was observed that the intercept (b) is close to zero. Therefore, the linearity is satisfactory in each instance and Beer's law is obeyed in the concentration range with $\lambda_{\max }=470 \mathrm{~nm}$ (Figure 5).

The LOD $\left(3 \times\left[\mathrm{SD}_{\text {blank }} /\right.\right.$ slope of curve $\left.]\right), \mathrm{LOQ}\left(10 \times\left[\mathrm{SD}_{\text {blank }} /\right.\right.$ slope of curve]) and molar absorptivity $(\varepsilon)\left(\mathrm{L} \mathrm{mol}^{-1} \mathrm{~cm}^{-1}\right)$ were $1.12 \mu \mathrm{g} \mathrm{mL}-1$, $3.74 \mu \mathrm{g} \mathrm{mL}^{-1}$ and $7.19 \times 10^{3}$ respectively (Table 1 ).

\section{Intra-day and inter-day precision}

The precision of the method was described by determining

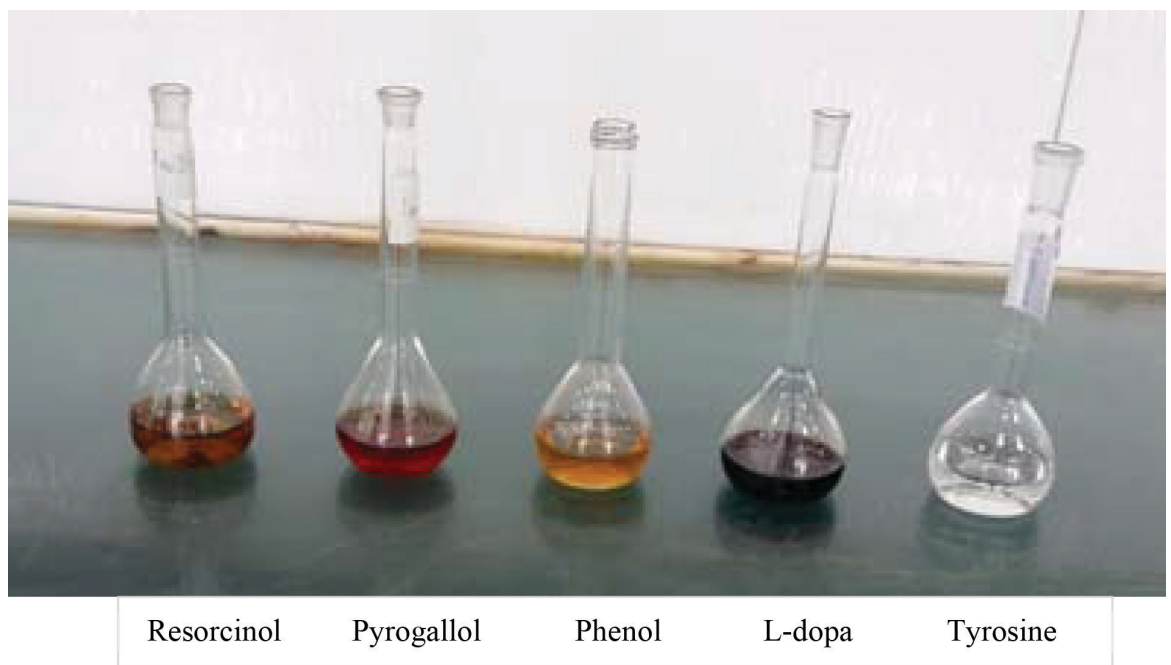

Figure 4. Selectivity of the method for L-DOPA detection 


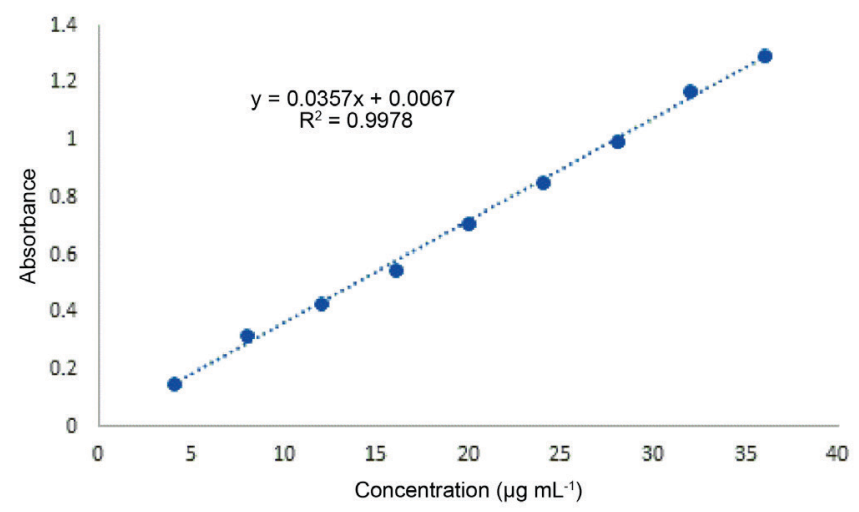

Figure 5. Calibration curve of standard L-DOPA

Table 1. Method validation parameters for the determination of L-DOPA using spectrophotometric method

\begin{tabular}{lc}
\hline Parameters & Analytical data \\
\hline Instrumental precision $(\mathrm{CV}, \%)(\mathrm{n}=5)$ & 0.16 \\
Repeatability $(\mathrm{CV}, \%)(\mathrm{n}=12)$ & 0.37 \\
Linearity Range $\left(\mu \mathrm{g} \mathrm{m}^{-1}\right)$ & $4-36$ \\
$\lambda$ max $(\mathrm{nm})$ & 470 \\
$\varepsilon\left(\mathrm{L} \mathrm{mol}^{-1} \mathrm{~cm}^{-1}\right)$ & $7.1944 \times 10^{3}$ \\
Sandell sensitivity $\left(\mu \mathrm{g} \mathrm{cm}^{-2}\right)$ & 0.0273 \\
Slope & 0.036 \\
Intercept & 0.0067 \\
Standard deviation of Slope $(\mathrm{SD})$ & \pm 0.002 \\
Standard deviation of intercept $(\mathrm{SD})$ & \pm 0.028 \\
Correlation co-efficient $(\mathrm{r})$ & 0.9978 \\
Accuracy $(\%)$ & $99.55-100.27$ \\
Limit of detection $\left(\mathrm{LOD}, \mu \mathrm{g} \mathrm{mL}{ }^{-1}\right)$ & 1.12 \\
Limit of quantification $(\mathrm{LOQ}, \mu \mathrm{g} \mathrm{mL}-1)$ & 3.74 \\
\hline
\end{tabular}

within-day and between-day precisions, expressed in percent and obtained by relative standard deviation RSD or coefficient of variation (CV). Three standard solutions containing 4, 20 and $28 \mu \mathrm{g} \mathrm{mL}-1$ of L-DOPA were analyzed in three replicates during the same day (intraday precision) and three consecutive days (inter-day precision). To assess the day-to-day precision of the method, fresh standard solutions were prepared each day since the L-DOPA is not sufficiently stable to allow use over a number of days. The intra-day and inter-day precision studies confirmed appropriate sample stability and method reliability. \%RSD values of intra and inter-day were found between $0.24-0.36 \%$ and $0.08-0.36 \%$, respectively indicating satisfactory precision since all the RSDs were $<2.0 \%$. In addition, in all cases, errors were calculated lower than $0.27 \%$ (Table 2).

Table 2. Evaluation of intra-day and inter-day precision for three different concentrations of L-DOPA

\begin{tabular}{cccccccc}
\hline $\begin{array}{c}\text { Concentration } \\
\left(\mu \mathrm{g} \mathrm{mL}^{-1}\right)\end{array}$ & $\begin{array}{c}\text { Intra-day } \\
\text { precision } \\
\text { L-dopa } \\
\text { found } \\
\left(\mu \mathrm{g} \mathrm{mL}^{-1}\right)^{\mathrm{a}}\end{array}$ & RSD \% RE\% & $\begin{array}{c}\text { Inter-day } \\
\text { precision } \\
\text { L-dopa } \\
\text { found } \\
\left(\mu \mathrm{g} \mathrm{mL}^{-1}\right)^{\mathrm{a}}\end{array}$ & RSD \% RE\% \\
\hline 4 & $4.12 \pm 0.24$ & 0.24 & 0.21 & $4.27 \pm 1.06$ & 1.05 & 0.27 \\
20 & $20.67 \pm 1.84$ & 0.36 & 0.13 & $20.11 \pm 1.83$ & 0.36 & 0.02 \\
28 & $28.39 \pm 1.94$ & 0.27 & 0.05 & $28.60 \pm 0.60$ & 0.08 & 0.08 \\
\hline
\end{tabular}

RE- Relative error; RSD- Relative standard deviation. ${ }^{a}$ Mean $\pm \mathrm{SD}, \mathrm{n}=3$.

\section{Accuracy/recovery and repeatability studies}

Accuracy of an analytical method is ascertained by the closeness between the reference value and the found value; it is confirmed by high accuracy of the corresponding method. The accuracy of our method was examined by performing recovery experiments at four concentrations by addition of different known amount of standard to approximately $5.1 \mathrm{mg}$ of L-DOPA. The results obtained for the accuracy of the method were summarized in Table 3. The recovery was found to be $101.04 \%, 100.27 \%, 99.55 \%$, and $100.25 \%$, respectively and the mean recovery values for all samples is $100.28 \%$ and RSD is within $0.66-1.38 \%$.

Table 3. Accuracy and recovery study of the spectrophotometric method for the determination of L-DOPA

\begin{tabular}{cccc}
\hline $\begin{array}{c}\text { Amount of } \\
\text { L-DOPA present } \\
(\mathrm{mg})\end{array}$ & Added $(\mathrm{mg})$ & Found $(\mathrm{mg})^{\mathrm{a}}$ & Recovery $(\%)^{\mathrm{a}}$ \\
\hline 5.06 & 1.29 & $6.46 \pm 0.09$ & $101.04 \pm 1.38$ \\
5.09 & 2.85 & $8.02 \pm 0.06$ & $100.27 \pm 0.76$ \\
5.05 & 3.46 & $8.56 \pm 0.08$ & $99.55 \pm 0.87$ \\
5.07 & 4.67 & $9.82 \pm 0.07$ & $100.25 \pm 0.66$ \\
\hline
\end{tabular}

$*$ Mean $\pm \mathrm{SD}, \mathrm{n}=5$.

\section{L-DOPA content in the herbal extracts}

As shown in Table 4, all seeds contain L-DOPA. The amount of L-DOPA varies in different seeds. The lowest amounts belong to Ks51273 and Ks51176 with value of $0.05 \%$ and $0.06 \%$ and the highest amounts are related to Ks 10001 and Ks 10003 with the values of $0.48 \%, 0.45 \%$ respectively. The average value of L-DOPA content in the 33 tested biotypes of Phaseolus vulgaris L. is approximately $0.30 \%$ and black seeds possess higher amounts of L-DOPA in comparison to yellow and brown types.

Accuracy of the method was also confirmed by the good recovery of added L-DOPA to the plant extracts of five randomLy selected Samples (Ks10001, Ks10014, Ks10033, Ks10025, Ks51176) (Table 5). The recovery and RSD values for these samples were obtained within the $99.57-100.92 \%$ and $0.460-1.397 \%$ which confirmed accuracy of the method for the detection of L-DOPA in herbal extracts. It also shows that there is no interference for the detection of L-DOPA in the presence of excipients in the herbal extracts.

The results of this method were compared with the results obtained with the HPLC method for seven random selected seeds and also for $M$. prurience $L$. as a reference plant. The statistical comparison is presented in Table 6 . The calculated t-values at the $95 \%$ confidence level did not exceed the theoretical values indicating no significant difference between this proposed method and a reference method (HPLC).

\section{Dark germination effect on the content of levodopa}

Seven seeds with variable range of L-DOPA which was measured by spectrophotometric method in previous section were selected. These seeds included Ks51273, Ks10017 and Ks10008 with the lowest value of L-DOPA, Ks10025 and Ks10032 with the average value of L-DOPA as well as Ks10023 and Ks10001 with the highest value of L-DOPA. The results of the present study showed that the L-DOPA value was improved during dark germination of the seeds, in all cases the L-DOPA content of the germinated sprouts increased comparing with control on day 0 . The increase in L-DOPA content 
Table 4. Variability in L-DOPA content (\%) in 33 biotypes of Phaseolus Vulgaris $\mathrm{L}$.

\begin{tabular}{|c|c|c|}
\hline Entry & Sample's code & L-DOPA content $(\%)^{\mathrm{a}}$ \\
\hline 1 & Ks10001 & $0.48 \pm 0.02$ \\
\hline 2 & Ks10002 & $0.39 \pm 0.10$ \\
\hline 3 & Ks10003 & $0.45 \pm 0.04$ \\
\hline 4 & Ks10004 & $0.28 \pm 0.21$ \\
\hline 5 & Ks10005 & $0.25 \pm 0.09$ \\
\hline 6 & Ks10007 & $0.39 \pm 0.14$ \\
\hline 7 & Ks10008 & $0.08 \pm 0.08$ \\
\hline 8 & Ks10009 & $0.36 \pm 0.05$ \\
\hline 9 & Ks 10010 & $0.35 \pm 0.17$ \\
\hline 10 & Ks10011 & $0.38 \pm 0.07$ \\
\hline 11 & Ks10012 & $0.32 \pm 0.11$ \\
\hline 12 & Ks10013 & $0.30 \pm 0.17$ \\
\hline 13 & Ks10014 & $0.39 \pm 0.22$ \\
\hline 14 & Ks10016 & $0.40 \pm 0.28$ \\
\hline 15 & Ks10017 & $0.05 \pm 0.05$ \\
\hline 16 & Ks10022 & $0.31 \pm 0.04$ \\
\hline 17 & Ks10023 & $0.41 \pm 0.13$ \\
\hline 18 & Ks10024 & $0.36 \pm 0.20$ \\
\hline 19 & Ks10025 & $0.24 \pm 0.36$ \\
\hline 20 & Ks10026 & $0.40 \pm 0.07$ \\
\hline 21 & Ks10027 & $0.33 \pm 0.14$ \\
\hline 22 & Ks10029 & $0.29 \pm 0.23$ \\
\hline 23 & Ks10030 & $0.28 \pm 0.04$ \\
\hline 24 & Ks10031 & $0.39 \pm 0.13$ \\
\hline 25 & Ks10032 & $0.34 \pm 0.19$ \\
\hline 26 & Ks10033 & $0.30 \pm 0.16$ \\
\hline 27 & Ks10034 & $0.36 \pm 0.08$ \\
\hline 28 & Ks10035 & $0.39 \pm 0.03$ \\
\hline 29 & Ks10037 & $0.36 \pm 0.11$ \\
\hline 30 & Ks51102 & $0.09 \pm 0.25$ \\
\hline 31 & Ks51176 & $0.06 \pm 0.29$ \\
\hline 32 & Ks51273 & $0.05 \pm 0.06$ \\
\hline 33 & Ks920176 & $0.26 \pm 0.12$ \\
\hline
\end{tabular}

Mean $\pm \mathrm{SD}, \mathrm{n}=3$. was observed during days 3-9 in Ks10001, Ks10008, Ks10017, Ks10023, and Ks10032; however, Ks10025 and Ks51273 showed similar results by day 6 . Further, from day 9 to day 12 , accumulation of L-DOPA was found to be decreased in all seeds studied (Table 7).

\section{Effect of the plant growth regulators (PGR) on cell growth of Phaseolus vulgaris $\mathbf{L}$.}

Maximum growth of callus was obtained in MS medium supplemented with $2,4-\mathrm{D}$ at $2.50 \mu \mathrm{mol} \mathrm{L} \mathrm{L}^{-1}$, IAA at $5.50 \mu \mathrm{mol} \mathrm{L}-1$, 2-ip at $3.00 \mu \mathrm{M}$, and BA at $2.00 \mu \mathrm{mol} \mathrm{L}-1$ (Table 8). Callus grown on medium supplemented with 2,4-D and IAA was pale yellowish. While callus grown on medium supplemented with BA and 2-iP was green and more compact. The maximum callus growth was found with cytokinins such as 2-iP and auxin (2,4-D). These findings conform to the reported results about Mucuna Pruriens L. by Janarthanam. ${ }^{37}$ The Remarkable thing is that, in all cases increasing PGR leads to reduced growth of callus.

\section{Effect of elicitors and precursor on the accumulation of L-DOPA}

Both the elicitors and precursors (methyl jasmonate and L-tyrosine) increased the accumulation of L-DOPA in the cell suspension cultures compared to the control of cultures from day 3 to day 12. Methyl jasmonate, caused to increase L-DOPA several folds during day 3 to day 9 , from day 9 to day 12, accumulation of L-DOPA was observed to be decreased (Table 9).

Accumulation of L-DOPA under the influence of precursor L-tyrosine was rather different comparing with methyl jasmonate used in the present study. L-tyrosine increased the L- DOPA production from day 3 to day 12 at all the concentrations tested (Table 10). The highest concentration of L-DOPA was obtained $\left(40.124 \pm 1.00 \mathrm{mg} \mathrm{g}^{-1}\right)$ on day 12 at $200 \mathrm{mg} \mathrm{L}^{-1}$ with a 17.75 -fold increase. Results showed that L-tyrosine can be used as natural and effective precursor for the synthesis of L-DOPA. ${ }^{38}$

Table 5. Accuracy and recovery study of the spectrophotometric method for the determination of L-DOPA in herbal extracts

\begin{tabular}{|c|c|c|c|c|c|}
\hline $\begin{array}{c}\text { Sample's code } \\
\text { (Approximately } 300 \mathrm{mg} \text { ) }\end{array}$ & $\begin{array}{c}\text { Amount of L-DOPA } \\
\text { added (mg) }\end{array}$ & $\begin{array}{l}\text { Theoretical content } \\
(\mathrm{mg})^{\mathrm{a}}\end{array}$ & $\begin{array}{l}\text { Amount found } \\
(\mathrm{mg})^{\mathrm{b}}\end{array}$ & Recovery $(\%)^{\mathrm{a}}$ & Repeatability (RSD \%) \\
\hline Ks10001 & 2.0 & 3.42 & $3.43 \pm 0.04$ & $100.29 \pm 1.27$ & 1.27 \\
\hline Ks10014 & 2.0 & 3.16 & $3.14 \pm 0.01$ & $99.57 \pm 0.48$ & 0.49 \\
\hline Ks10033 & 2.0 & 2.89 & $2.88 \pm 0.02$ & $99.65 \pm 0.92$ & 0.92 \\
\hline Ks 10025 & 2.0 & 2.71 & $2.70 \pm 0.03$ & $99.87 \pm 1.40$ & 1.40 \\
\hline Ks51176 & 2.0 & 2.17 & $2.19 \pm 0.01$ & $100.92 \pm 0.46$ & 0.46 \\
\hline
\end{tabular}

${ }^{a}$ Theoretical values have been obtained using Table 4 for approximately $300 \mathrm{mg}$ of sample extract, which has been added with $2 \mathrm{mg}$ of L-DOPA. ${ }^{\mathrm{b}} \mathrm{Mean} \pm \mathrm{SD}, \mathrm{n}=3$.

Table 6. Results of the determination of L-DOPA content in some seeds by the Spectrophotometric method and compered with HPLC Method

\begin{tabular}{|c|c|c|c|c|c|c|c|c|}
\hline \multirow{2}{*}{ Entry } & \multirow{2}{*}{ Sample's code } & \multicolumn{3}{|c|}{ Based on UV spectrophotometry method } & \multicolumn{4}{|c|}{ Based on HPLC method } \\
\hline & & Recovery (\%) & $\mathrm{SD}^{\mathrm{a}}$ & $\operatorname{RSD}(\%)$ & Recovery $(\%)$ & $\mathrm{SD}^{\mathrm{a}}$ & $\operatorname{RSD}(\%)$ & $\mathrm{t}^{\mathrm{b}}$ \\
\hline 1 & Ks10008 & 99.41 & 0.57 & 0.91 & 99.76 & 0.30 & 0.86 & 1.21 \\
\hline 2 & Ks10016 & 99.82 & 0.23 & 0.69 & 99.53 & 0.27 & 0.42 & 0.93 \\
\hline 3 & Ks 10025 & 99.11 & 0.13 & 0.82 & 99.80 & 0.24 & 0.75 & 0.65 \\
\hline 4 & Ks10031 & 99.35 & 0.47 & 0.77 & 99.75 & 0.31 & 0.32 & 1.25 \\
\hline 5 & Ks10037 & 99.30 & 0.50 & 1.10 & 100.1 & 0.37 & 0.89 & 1.34 \\
\hline 6 & Ks51176 & 99.70 & 0.10 & 0.89 & 99.49 & 0.29 & 0.71 & 0.86 \\
\hline 7 & Ks920176 & 99.10 & 0.33 & 0.76 & 99.45 & 0.23 & 0.39 & 0.74 \\
\hline 8 & M. pruriens & 99.54 & 0.21 & 0.58 & 99.36 & 0.12 & 0.48 & 0.49 \\
\hline
\end{tabular}

${ }^{\mathrm{a}}$ Average of 6 determinations. ${ }^{\mathrm{b}}$ Theoretical value at $95 \%$ confidence level (2.57). 
Table 7. L-DOPA content (\%) in the dark germinating Phaseolus vulgaris L sprouts

\begin{tabular}{|c|c|c|c|c|c|c|}
\hline Entry & Sample's code & Day 0 & Day 3 & Day 6 & Day 9 & Day 12 \\
\hline 1 & Ks10001 & 0.48 & 0.60 & 1.11 & 1.48 & 0.96 \\
\hline 2 & Ks10008 & 0.08 & 0.11 & 0.21 & 0.28 & 0.18 \\
\hline 3 & Ks10017 & 0.05 & 0.09 & 0.24 & 0.35 & 0.20 \\
\hline 4 & Ks10023 & 0.41 & 0.53 & 0.97 & 1.31 & 0.89 \\
\hline 5 & Ks10025 & 0.24 & 0.35 & 1.19 & 0.84 & 0.72 \\
\hline 6 & Ks10032 & 0.34 & 0.43 & 0.78 & 1.04 & 0.68 \\
\hline 7 & Ks51273 & 0.05 & 0.09 & 0.35 & 0.23 & 0.11 \\
\hline
\end{tabular}

Table 8. Effect of PGR on callus culture of Phaseolus vulgaris L.

\begin{tabular}{|c|c|c|c|}
\hline PGR & $\begin{array}{c}\text { Concentration } \\
(\mu \mathrm{M})\end{array}$ & $\mathrm{FW}\left(\mathrm{g} \mathrm{L}^{-1}\right)$ & $\mathrm{DW}\left(\mathrm{g} \mathrm{L}^{-1}\right)$ \\
\hline \multirow{7}{*}{$2,4-\mathrm{D}$} & 0.5 & $21 \pm 0.97$ & $1.5 \pm 1.24$ \\
\hline & 1.5 & $27 \pm 1.34$ & $2.3 \pm 0.89$ \\
\hline & 2.5 & $49 \pm 0.69$ & $3.8 \pm 0.79$ \\
\hline & 4.5 & $41 \pm 0.81$ & $3.1 \pm 1.35$ \\
\hline & 11.0 & $36 \pm 1.21$ & $2.7 \pm 0.62$ \\
\hline & 22.5 & $25 \pm 1.36$ & $1.2 \pm 1.01$ \\
\hline & 45.0 & $19 \pm 0.84$ & $0.9 \pm 1.44$ \\
\hline \multirow{7}{*}{ IAA } & 0.5 & $24 \pm 1.84$ & $2.2 \pm 0.71$ \\
\hline & 1.5 & $26 \pm 0.54$ & $1.8 \pm 0.89$ \\
\hline & 3.0 & $32 \pm 0.65$ & $2.3 \pm 1.37$ \\
\hline & 5.5 & $45 \pm 1.65$ & $4.1 \pm 0.74$ \\
\hline & 14.0 & $38 \pm 0.94$ & $2.9 \pm 1.21$ \\
\hline & 28.0 & $35 \pm 1.54$ & $2.7 \pm 0.81$ \\
\hline & 57.5 & $32 \pm 1.77$ & $3.5 \pm 1.10$ \\
\hline \multirow{7}{*}{$\mathrm{BA}$} & 0.4 & $14 \pm 1.37$ & $1.1 \pm 0.96$ \\
\hline & 1.5 & $28 \pm 1.09$ & $2.3 \pm 0.73$ \\
\hline & 2.0 & $44 \pm 1.40$ & $3.5 \pm 0.90$ \\
\hline & 4.5 & $22 \pm 0.81$ & $1.9 \pm 1.10$ \\
\hline & 11.0 & $20 \pm 1.06$ & $1.5 \pm 1.04$ \\
\hline & 22.5 & $18 \pm 1.59$ & $1.1 \pm 0.64$ \\
\hline & 44.0 & $16 \pm 1.29$ & $1.2 \pm 1.27$ \\
\hline \multirow{7}{*}{ 2-iP } & 0.6 & $17 \pm 0.95$ & $0.9 \pm 1.33$ \\
\hline & 1.5 & $21 \pm 0.76$ & $1.6 \pm 1.53$ \\
\hline & 3.00 & $48 \pm 1.00$ & $4.2 \pm 1.11$ \\
\hline & 4.50 & $26 \pm 1.32$ & $2.7 \pm 1.22$ \\
\hline & 12.00 & $22 \pm 0.81$ & $1.6 \pm 1.01$ \\
\hline & 24.50 & $15 \pm 0.79$ & $1.0 \pm 0.91$ \\
\hline & 50.00 & $11 \pm 1.24$ & $0.8 \pm 1.59$ \\
\hline
\end{tabular}

Results represent mean \pm SD of three replicated experiments. FW: Fresh weight, DW: Dry weight, PGR: Plant growth regulators, 2,4-D: 2,4-dichlorophenoxyacetic acid, IAA: Indole-3-acetic acid, BA: 6-benzylaminopurine, 2-iP: 2-isopentenyl adenine.

Table 9. Effect of elicitor methyl jasmonate on the production of L-DOPA $\left(\mathrm{mg} \mathrm{g}^{-1}\right)$ in suspension cultures of Phaseolus vulgaris $\mathrm{L}$.

\begin{tabular}{cccccc}
\hline \multirow{2}{*}{ Day } & \multicolumn{5}{c}{ Concentration of methyl jasmonate in $\mu \mathrm{mol} \mathrm{L}{ }^{-1}$} \\
\cline { 2 - 6 } & Control & 50 & 100 & 150 & 200 \\
\hline 3 & $0.95 \pm 0.05$ & $1.53 \pm 0.82$ & $3.01 \pm 0.12$ & $4.32 \pm 1.42$ & $9.22 \pm 1.02$ \\
6 & $1.31 \pm 0.23$ & $2.68 \pm 1.32$ & $5.68 \pm 0.42$ & $6.31 \pm 0.87$ & $10.65 \pm 1.45$ \\
9 & $2.01 \pm 0.12$ & $4.15 \pm 0.65$ & $8.42 \pm 0.72$ & $9.26 \pm 0.72$ & $14.55 \pm 1.67$ \\
12 & $2.26 \pm 1.09$ & $3.25 \pm 0.21$ & $6.51 \pm 0.10$ & $5.55 \pm 0.56$ & $11.37 \pm 1.25$ \\
\hline
\end{tabular}

Table 10. Effect of precursor L-tyrosine on the production of L-DOPA $\left(\mathrm{mg} \mathrm{g}^{-1}\right)$ in suspension cultures of Phaseolus vulgaris $\mathrm{L}$.

\begin{tabular}{cccccc}
\hline \multirow{2}{*}{ Day } & \multicolumn{5}{c}{ Concentration of L-tyrosine in mmol L } \\
\cline { 2 - 6 } & Control & 50 & 100 & 150 & 200 \\
\hline 3 & $0.95 \pm 0.05$ & $3.68 \pm 0.08$ & $7.65 \pm 0.78$ & $9.65 \pm 1.34$ & $15.21 \pm 1.25$ \\
6 & $1.31 \pm 0.23$ & $5.55 \pm 0.03$ & $11.37 \pm 0.12$ & $17.85 \pm 0.09$ & $22.01 \pm 1.04$ \\
9 & $2.01 \pm 0.12$ & $9.37 \pm 0.72$ & $16.37 \pm 1.11$ & $21.21 \pm 0.41$ & $34.14 \pm 1.65$ \\
12 & $2.26 \pm 1.09$ & $10.36 \pm 1.09$ & $20.35 \pm 1.32$ & $32.35 \pm 0.65$ & $40.12 \pm 1.00$ \\
\hline
\end{tabular}

\section{CONCLUSION}

In conclusion, practical, efficient, environmentally-friendly, accurate and rapid spectrophotometric determination of L-DOPA obtained from different biotypes of Phaseolus vulgaris was reported. The method is also economic since expensive instrumentations such as HPLC and HPTLC are not involved. It is based on the reaction of L-DOPA with $\mathrm{NaNO}_{2}$ in acidic medium to form an unstable yellow solution which converted to stabilized red soution by addition of sodium hydroxide which is measurable at $470 \mathrm{~nm}$. It should be noted that the method is highly selective toward L-DOPA in the presence of other phenolic compounds such as phenol, resorcinol, and tyrosine. Validation of this method was applied succesfully by comparision with the HPLC method. The calculated t-values showed that, there is no significant difference between the two methods. Our results revealed that amoung the tested 33 biotypes of $P$. vulgaris, black seeds possessed higher amounts of L-DOPA in comparison to yellow and brown types. They may be more efficient for the therapeutic purposes and preparation of herbal supplement. Considering the fact that L-DOPA is still the gold standard for treating Parkinson's disease, the method can play an important role in determination of L-DOPA in herbal formulations. We also determined L-DOPA content in seed dark germination and callus culture of Phaseolus vulgaris L. in different conditions. Seeds dark germination and plant tissue cultures have been proposed as useful techniques to increase production of L-DOPA. Our results confirmed that tyrosine significantly increased the concentration of L-DOPA and thus it could be applied successfully to large-scale production of L-DOPA.

\section{ACKNOWLEDGEMENTS}

Authors acknowledge finacial support from Reseach Council of Tehran University Medical Sciences and Iran National Science Foundation (INSF).

\section{REFERENCES}

1. Lang, A.; Lozano, A.; N. Engl. J. Med. 1998, 339, 1044.

2. Kofman, O.; Can. Med. Assoc. J. 1971, 104, 483.

3. Guggenheim, M.; Z. Physiol. Chem. 1913, 88, 276. 
4. Apaydin, H.; Ertan, S.; Ozekmekci, S.; Mov. Disord. 2000, 15, 164.

5. Randhir, R.; Shetty, P.; Shetty, K.; Process Biochem. 2002, 37, 1247; Shetty, P.; Atallah, M. T.; Shetty, K.; Process Biochem. 2002, 37, 1285; Randhir, R.; Shetty, K.; Process Biochem. 2004, 39, 1775; Randhir, R.; Vattem, D; Shetty, K.; Innovations Food Sci. Emerging Technol. 2004, 5, 235; Raghavendra, S.; Ramesh, C. K.; Kumar Vand Moinuddin Khan, M. H.; Front. Life Sci. 2011, 5, 127.

6. Betto, P.; Ricciarello, G.; Giabenedetti, M.; Lucarelli, C.; Ruggeri, S.; Stocchi, F.; J. Chromatogr. A. 1988, 459, 341.

7. British Pharmacopoeia, HMSO Publication Centre, London, Vol. I and II. 1980, 781: 254, 535.

8. Cannazza, G.; Stefano, A.D.; Mosciatti, B.; Braghiroli, D.; Baraldi, M.; Pinnen, F.; Sozio, P.; Benatti, C.; Parenti, C.; J. Pharm. Biomed. Anal. 2005, 36, 1079.

9. Husain, S.; Sekar, R.; Nageswara Rao, R.; J. Chromatogr. A. 1994, 687, 351.

10. Issa, Y. M., Hassoun, M. E. M.; Zayed, A. G.; J. Liq. Chromatogr. Relat. Technol. 2011, 34, 2433

11. Kafil, J. B.; Dhingra, B. S.; J. Chromatogr. A. 1994, 667, 175.

12. Li, S. F.; Wu, H. L.; Yu, Y. J.; Li, Y. N.; Nie, J. F.; Fu, H. Y.; Yu, R. Q.; Talanta 2010, 81, 805.

13. Michotte, Y.; Moors, M.; Deleu, D.; Herregodts, P.; Ebinger, G.; $J$. Pharm. Biomed. Anal. 1987, 5, 659.

14. Raut, P. P.; Charde, S. Y.; Luminescence 2014, 29, 762.

15. Sravanthi, D.; Anusha, M.; Madhavi, S.; Firdose, S.; Nalluri, B. N.; J. Chem. Pharm. Res. 2013, 5, 422.

16. Titus, C. D.; August, F. T.; Yeh, C. K.; Eisenhandler, R.; Bayne, F. W.; Musson, G. D.; J. Chromatogr. B 1990, 99, 87.

17. The United State Pharmacopoeia, XXI, $21^{\text {st }}$ revision, The US Pharmaceutical Convention Inc., Rockville. 1987, pp. 585-586.

18. Bo-Young, C.; Hyun-Man, B.; Byung-Chul, S.; Moon-Chan, K.; EuyNeyng, K.; Tae-Suk, S.; Hyoung-Koo, L.; Kyung-Sub, S.; J. Korean. Soc. Magn. Reson. Med. 2000, 4, 19; Talebpour, Z.; Haghgoo, S.; Shamsipur, M.; Anal. Chim. Acta. 2004, 506, 97.

19. Alam, S. M.; Karim, M. M.; Lee, S. H.; Wabaidur, S. M.; Chung, H. Y.; Choi, J. H.; Kang, M.; Luminescence 2008, 23, 327; Deftereos, N. T.; Calokerinos, A. C.; Efstathiou, C. E.; Analyst 1993, 118, 627; Nozaki, O.; Iwaeda, T.; Moriyama, H.; Kato, Y.; Luminescence 1999, 14, 123; Zhao, S.; Wenling, B.; Bing, W.; Min, H.; Talanta 2007, 15, 142.

20. Bell, C. E.; Somerville, A. R.; Biochem. J. 1966, 98, 1; Kazuhizo, I.; J. Chromatogr. A. 1975, 105, 135

21. Seki, T.; Wada, H.; J. Chromatogr. A. 1975, 114, 227.

22. Mennickent, S.; Nail, M.; Vega, M.; de Diego, M.; J. Sep. Sci. 2007, 30 1893.
23. Doshi, P. S.; Edwards, D. J.; J. Chromatogr. A. 1981, 210, 505; Satoshi, K.; Zenzo, T.; Chem. Pharm. Bull. 1968, 16, 1091.

24. Ricebery, L. J.; Vunakis, H. V.; Levin, L.; Anal. Biochem. 1974, 60, 551.

25. Amin, D.; Analyst 1986, 111, 255; Salem, F. B.; Anal. Lett. 1993, 26, 1959.

26. Bishop, E.; Houssein, W.; Analyst. 1984, 109, 627; Ensafi, A. A.; Arabzadeh, A.; Karimi-Maleh, H.; J. Braz. Chem. Soc. 2010, 21, 1572; Kozminski, K. D.; Gutman, D. A.; Davilla, V.; Sulzer, D.; Ewing, A. G.; Anal. Chem. 1998, 70, 3123; Teixeira, M. F. S.; Bergamini, M. F.; Marques, C. M. P.; Bocchi, N.; Talanta. 2004, 63, 1083.

27. Zhang, L.; Chen, G.; Hu, Q.; Fang, Y.; Anal. Chim. Acta. 2001, 431, 287.

28. Badawy, S. S.; Issa, Y. M.; Tag-Eldin, A. S.; Electroanalysis 1996, 8, 1060.

29. Lv, L.; Jiang, W.; Zhou, S.; Huang, X.; Shi, X.; Lv, C.; Wu, L.; Xu, C.; Chromatographia. 2010, 2, 751.

30. Unendi, G.; Pamuk, F.; Turk. J. Chem. 1999, 23, 269.

31. Siddiqui, M. R.; AlOthman, Z. A.; Rahman, N.; Arabian J. Chem. 2017, 10 (S1), S1409.

32. Ramya, K. B.; Thaakur, S.; Ancient Science of Life 2007, 27, 50.

33. Afkhami, A.; Khatami, H.; Anal. Chem. 2003, 58, 135; Chamsaz, M.; Safavi, A.; Fadaee, J.; Anal. Chim. Acta. 2007, 603, 140; Gowda, B. G.; Melwanki, M. B.; Seetharamappa, J.; Anal. Sci. 2001, 17, 533; Madrakian, T.; Afkhami, A.; Borazjani, M.; Bahram, M.; Bull. Mater. Sci. 2004, 25, 1764; Helaleh, M. I. H.; Abu-Nameh, E. S. M.; Chem. Analityczna. 1998, 43, 225; Madrakian, T.; Afkhami, A.; Khalafi, L.; Mohammadnejad, M.; J. Braz. Chem. Soc. 2006, 17, 1259; Nagaraja, P.; Shrestha, A. K.; Shivakumar, A.; Saeed Al-Tayar, N. G.; Gowda, A. K.; Quim. Nova 2011, 34, 373; Patil, V. P.; Devdhe, S. J.; Kawde, R.; Kulkarni, V. S.; Nagmoti, V. J.; Patil, R. D.; Kale, S. H.; Int. J. Pharm. Sci. 2012, 4, 711 .

34. Pieris, N.; Jansz, E. R.; Dharmadara, H. M.; J. Natl. Sci. Found. Sri. 1980, 8, 35; Upadhyay, V.; Tiwari, A. K.; Sharma, N.; Joshi, H. M.; Singh, B. P.; Kalakoti, B. S.; Int. J. Pharma. Sci. Drug Res. 2012, 1, 135; Khozaei, M.; Ghorbani, F.; Mardani, G.; Emamzadeh, R.; J. HerbMed Pharmacol. 2014, 3, 61; Modi, K. P.; Patel, N. M.; Goyal, R. K.; Chem. Pharm. Bull. 2008, 56, 357; MohSeni Mehran, S. M.; GolShani, B., J. Clin. Diagn. Res. 2013, 7, 1004

35. Murashige, T.; Skoog, F.; Physiol. Plant. 1962, 15, 473.

36. Janarthanam, B.; Gopalkrishnan, M.; Sekar, T.; J. Sci. Ind. Res. 2010, $45,243$.

37. Janarthanam, B.; Sumathi, E.; Asian J. Pharm. Clin. Res. 2015, 8, 282.

38. Pattison, D. I.; Dean, R. T.; Davis, M. J.; Toxicology. 2002, 177, 23. 